\title{
France seeks revised role in space station
}

Munich. Prompted by France, the council of the European Space Agency (ESA) agreed last week to consider a new proposal for Europe's contribution to the international space station. Rather than the planned space laboratory, which would be built by Germany and Italy, it is proposing a crew transfer and re-entry vehicle (CTRV), which would probably be built in France.

This new proposal was first announced by François Fillon, French minister for information technology and telecommunications, at the launch of the military satellite Helios in French Guyana earlier this month. But it could delay a final decision on Europe's exact role in the space station.

Until the beginning of this year, ESA's proposed contributions to the space station had three elements: a crew rescue vehicle (CRV), an Automated Transfer Vehicle (ATV) to transfer cargo to the space station, and the European laboratory module, known as the Columbus orbital facility (COF).

But after Germany and France, the two major participants in the pro- All aboard: the Crew Rescue Vehicle (CRV) would gramme, demanded a halving of the form the basis of a new space station component. planned ECU3.5-billion (US\$4.62-billion) costs between 1996 and 2000, it became impossible to maintain all three elements. In March, ESA therefore put forward a revised proposal from which the CRV had been removed.

In response, France said that it was no longer prepared to meet its previous commitment to the programme, despite being allocated prime responsibility for the lowcost ATV. In contrast, Germany, which would lead the COF project, was happy with the new proposal.

But ESA has still not been able to raise the full costs of this revised proposal (see Nature 374, 586; 1995). Only ECU1.4 billion of the ECU1.8 billion required between the years 1996 and 2000 has been definitely committed - and this assumes that Italy will be able to pay its promised ECU300 million that it would like to contribute. This failure has given France the opportunity to request ESA to study a proposal that it finds more acceptable.

\section{Technology office: now it's up, now it's down}

Washington. The Office of Technology Assessment (OTA), which provides the US Congress with analysis of science and technology issues, has returned to the critical list after the Senate rejected by 54 votes to 45 an amendment to keep the threatened office alive.

Last month, the House of Representatives unexpectedly voted by 220 to 204 to retain the OTA's functions within the Library of Congress (see Nature 375, 711;
ESA has now developed a plan to reduce costs further, to ECU1.5 billion, by extending the construction timetable of the two remaining elements. But ESA's council has also accepted a French request to cost a second proposal, based on combination of the CRV and the ATV.

The two options reflect a fundamental difference in philosophy over the space station between Germany and France - both driven by their own industrial interests.

\section{IMAGE UNAVAILABLE FOR COPYRIGHT REASONS}

France sees the CTRV as an opportunity to develop the techniques required to establish a lead in re-entry technology.

It hopes that the vehicle could be a forerunner of the space plane Hermes which it had planned to build before financial difficulties hit ESA. France also claims that independence in re-entry technology should be an important political aim for Europe.

Germany, in contrast, supports the COF as a way of participating fully in the use of the space station for scientific experiments. It also argues that the construction of the laboratory represents a considerable technological challenge for European industry, primarily in the development of data management and life support systems.

If the COF is built, as ESA is currently proposing, Europe would be allocated 7.8 per cent of the whole station's experimental use, and this would increase to 9 per cent if ESA wins responsibility for providing a regular boost for the station back into its

1995). Senators who voted to close the 170strong office last week included friends of science such as Carol Moseley-Braun (Democrat, Illinois) and Mark Hatfield (Republican, Oregon).

The Senate vote could result in the death of the OTA when the budget bills of the two houses are combined in September, as virtually all of the senators and congressmen taking part in the conciliation conference are pledged to close it. C. M. correct orbit. If the $\mathrm{COF}$ were to be replaced by the CTRV, it would be entitled to only about 3 per cent of use, according to calculations made by the German space agency, DARA.

France appears unconcerned at this prospect. "The French scientific community is not that interested in using the station; it is more interested in astronomy and planetology, which exploit satellite data, than microgravity," says André Lebeau, president of CNES, the French space agency. An additional advantage would be that ESA's contributions to the common operational costs of the space station would also fall if its utilization share was lower.

Germany does not have unqualified support from its own scientific community, which in the past has questioned the costeffectiveness of the experimental opportunities offered by the station, given that its own strengths lie in astrophysics. "We have a small scientific population with interest in microgravity," concedes Jan-Baldem Mennicken. But, accepting that money spent on the station would never in any case be redirected to them, scientists are no longer arguing the case.

Germany's position is now firmly behind the COF-ATV option: "it fulfils all the agreed goals of utilization and cargo transportation," says a DARA spokesman. Moreover, it has the support of the United States and has already been integrated into the intergovernmental draft agreement on space station participation (between Japan, Canada, United States, Russia, Europe). "The United States has told us that the laboratory is our entry ticket to the international space station", he says.

The CTRV option must be developed very quickly if it is to have a serious chance of being considered. While the COF-ATV option has financially binding agreements from industry for all of its parts, equivalent costings for the CTRV have not been carried out. Yet it has a very strict deadline, as it must be available in 2002 when the ageing Soyuz rescue vehicle is phased out. (The United States and Russia are negotiating its replacement).

ESA will now cost out France's proposal during August, and member states will spend September deciding which of the two competing options should be brought to October's ESA ministerial meeting, when a final decision on European participation in the space station must be decided.

Publicly, France and Germany are stressing heavily their interest in reaching agreement as soon as possible. But given their different viewpoints, ESA could be forced to ask the ministers to make the final choice - which could itself result in a deadlock that could postpone any decision. 